\title{
Computational Method for Estimating Contact Parameters and Service Life of Cylindrical Metal-Polymer Sliding Guides
}

\author{
M. Chernets ${ }^{a}, *$, A. Kornienko ${ }^{a}$, S. Fedorchuk ${ }^{a}$, Yu. Chernets ${ }^{a}$ \\ ${ }^{a}$ Aerospace Faculty, National Aviation University, Lubomyr Huzar 1, 03058 Kyiv, Ukraine
}

Keywords:

Cylindrical metal-polymer guide Computational method Epoxy composite materials Maximum contact and tribocontact pressures

Contact and tribocontact angles Service life

* Corresponding author:

Myron Chernets

E-mail: myron.czerniec@gmail.com

Received: 30 January 2021

Revised: 11 March 2021

Accepted: 30 March 2021

\begin{abstract}
A B S T R A C T
The method of calculating the contact strength and service life of cylindrical metal-polymer sliding guides (linear bearings) based on the author's research methodology of the wear kinetics of materials during sliding is given. The influence of load, bushing diameter and radial clearance on the maximum initial pressures in the guide is investigated. According to the developed mathematical model of wear the estimation of influence of composite bushing wear on change of contact parameters such as initial contact pressure and contact angle is carried out. The prediction calculation of guide service life depending on the above-stated factors is also carried out. Quantitative and qualitative regularities of influence of the accepted factors on contact pressure and service life of metal-polymer sliding guides are established.
\end{abstract}

(C) 2021 Published by Faculty of Engineering

\section{INTRODUCTION}

Guides are widely used to keep in contact the moving parts of various equipment and mechanisms. The most common in mechanical engineering are the guides of rectilinear motion. Cylindrical guides (linear bearings) along with plain guides are widely used in many areas of human activity. In particular, in various machines and equipment: forging and pressing equipment, metal - cutting machines, positioning drives, lifting and transport mechanisms, packing equipment, laboratory and medical equipment, equipment for food industry, equipment for wood and plastic processing, measuring devices, etc. With regard to metalpolymer guides, metals and polymer composites for conjugated parts differ significantly in strength and wear resistance.

Despite the practical necessity of design calculation of their service life or wear at the design stage, appropriate computational methods have not been developed for cylindrical sliding guides. Computational methods for sliding bearings with metal elements [1 - 5] were not used to predict the durability or wear of this type of guides with metal elements, and 
even more so to predict the durability of metalpolymer guides. These methods could be used to determine the contact parameters, but even in guides with metal elements such studies have not been conducted. Only in [6] by the method of triboelements the wear of a thin elastic layer of sliding bearing rigid bushing during reciprocating motion was determined. In [7], and later in [10 - 13] the research method of sliding bearings with metal elements is given, based on the author's methodology of research of materials wear kinetics at sliding friction. According to this method, the wear kinetics of cylindrical sliding guides with metal elements was studied in [8-10]. In [16], the calculation of contact parameters and friction forces in metal cylindrical sliding guides was performed.

Instead, the literature presents quite widely the results of experimental and numerical studies of sliding systems with reciprocating motion of pneumatic cylinders [18 - 20, 23, 28] and hydraulic cylinders [17, 21, 22, 24 - 27]. The main task of such studies is to assess the friction forces in the seals of the piston and rod, taking into account their geometry, diameter, operating conditions in the cylinders (pressure, speed, type of friction, etc.). However, there is no research on modeling their resource and wear, which occurs under the influence of their own weight.

The article presents the method for calculating metal-polymer cylindrical sliding guides with the bushing made of polymer composites Moglice and DK6 and the results of calculating the parameters of contact and resource.

\section{PROBLEM FORMULATION}

Cylindrical guides of rectilinear reciprocating motion are shown in Fig. 1. The slider (carriage) performs cyclic reciprocating movements on one (Fig. 1,a) or two (Fig. 1,b) cylindrical bases.

The considered cylindrical guide is modeled by an elastic base 2 , along which an elastic slider 3 with a pressed-in bushing 1 performs a reciprocating motion at a constant speed $v$ (Fig. 2 ). There is a radial clearance $\varepsilon=R_{1}-R_{2}$ in the joint. The elastic characteristics and wear resistance of the guide materials are significantly different. The slider 3 is under the influence of the working force $F$, which leads to the appearance of unknown contact pressures $p(\alpha)$ in the contact area $2 \alpha_{0}$. The solution is made as for the plane problem of the elasticity theory for an assembly loaded with a radial force $N=F / l_{1}$ reduced to a unit length of the bushing.

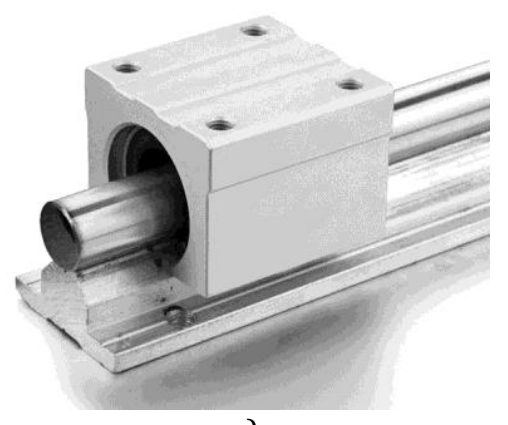

a)

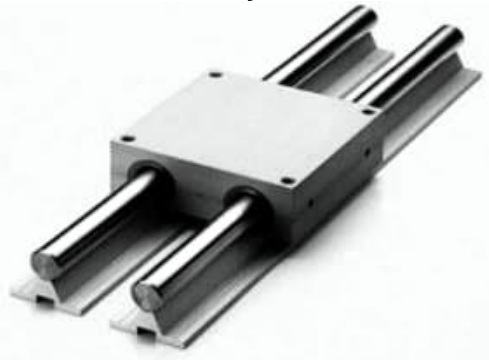

b)

Fig. 1. Cylindrical sliding guides with one (a) and two (b) bases

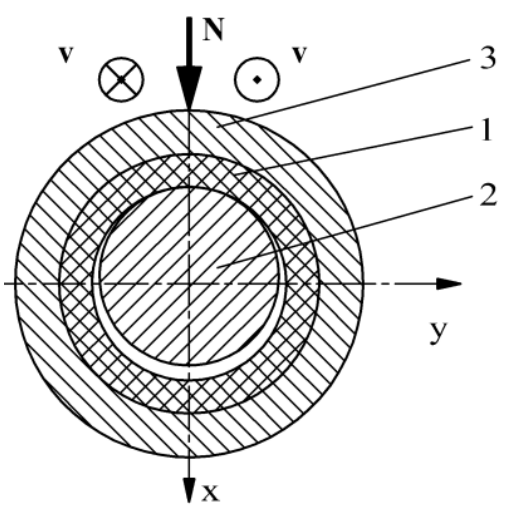

a)

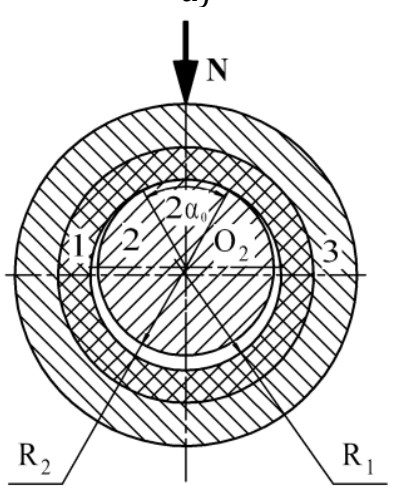

b)

Fig. 2. Schemes of cylindrical sliding guides: a) general, b) calculated 


\section{DETERMINATION OF INITIAL CONTACT PRESSURES}

The main equation of the considered plane contact problem for determining the arising contact pressures in the conjugation of cylinders of close radii at their internal contact is presented in [10]

$$
\begin{gathered}
c_{1} \int_{-\alpha_{0}}^{\alpha_{0}} \cot \frac{\alpha-\theta}{2} p^{\prime}(\theta) d \theta=c_{2} p(\alpha)+c_{3} \int_{-\alpha_{0}}^{\alpha_{0}} p(\alpha) d \alpha \\
+c_{4} \cos \alpha \int_{-\alpha_{0}}^{\alpha_{0}} p(\alpha) \cos \alpha d \alpha+\frac{\varepsilon}{R^{2}},
\end{gathered}
$$

where $p^{\prime}(\theta)=d p / d \theta ; \alpha$ is the polar angle; $-\alpha_{0} \leq \alpha \leq \alpha_{0}, 0 \leq \alpha \leq \pm \theta, 0 \leq \theta \leq \pm \alpha_{0} ;$

$$
\begin{gathered}
c_{1}=\frac{1}{8 \pi}\left(\frac{1+\kappa_{1}}{G_{1} R_{1}}+\frac{1+\kappa_{2}}{G_{2} R_{2}}\right) ; c_{2}=\frac{1}{4}\left(\frac{1-\kappa_{1}}{G_{1} R_{1}}-\frac{1-\kappa_{2}}{G_{2} R_{2}}\right) ; \\
c_{3}=\frac{1+\kappa_{1}}{8 \pi G_{1} R_{1}} c_{4}=\frac{1}{2 \pi}\left(\frac{\kappa_{1}}{G_{1} R_{1}}+\frac{1}{G_{2} R_{2}}\right) ;
\end{gathered}
$$

$G_{1}, G_{2}$ are the conjugation materials shear modules; $\mu_{1}, \mu_{2}$ are Poisson's ratios; $\kappa=3-4 \mu$ is the plane strain state; $G=E(1+\mu) / 2 ; E$ is Young's modulus.

The collocation method [7] is used for the approximate solution of equation (1). Accordingly, the contact pressure function is taken for one collocation point $\alpha= \pm 0.5 \alpha_{0}$ in the form

$$
p(\alpha) \approx E_{0} \varepsilon \sqrt{\tan ^{2} \frac{\alpha_{0}}{2}-\tan ^{2} \frac{\alpha}{2}},
$$

where $E_{0}=\left(e_{4} / R\right) \cos ^{2}\left(\alpha_{0} / 4\right)$ is the collocation coefficient; $e_{4}=4 E_{1} E_{2} / Z$, $Z=\left(1+\kappa_{1}\right)\left(1+\mu_{1}\right) E_{2}+\left(1+\kappa_{2}\right)\left(1+\mu_{2}\right) E_{1}$.

Maximum initial contact pressure $p(0)$ arises at $\alpha=0$ :

$$
p(0)=E_{0} \varepsilon \tan \left(\alpha_{0} / 2\right) .
$$

The initial contact semiangle $\alpha_{0}$ at a given value of the load $N$ is determined from the condition of equilibrium of the forces applied to the element 2 , by the equation $[7,10,12]$ :

$$
N=R \int_{-\alpha_{0}}^{\alpha_{0}} p(\alpha) \cos \alpha d \alpha=4 \pi R E_{0} \varepsilon \sin ^{2}\left(\alpha_{0} / 4\right) .
$$

For this purpose, the method of successive approximations is used, when angle $\alpha_{0}$ is from the condition of equality of the right and left parts of equation (4).

\section{MATHEMATICAL MODEL OF THE STUDY OF WEAR}

Here, to solve the considered tribocontact problem, a previously developed phenomenological mathematical model of material wear during sliding friction is used [7, $10,13]$. The wear kinetics of tribocouple materials is considered to be a fatigue process with different wear rates depending on the conditions under the action of friction forces, ie it is a process of frictional fatigue. This is evidenced by the literature data on the materials wear regularities during sliding and the results of the experimental studies conducted by the authors. In view of this, the concept of frictionalfatigue destruction of surface layers (wear) during sliding was based on the following hypothesis: the rate or intensity of linear wear of tribosystem materials depends on the level of specific friction forces occurring in the tribocontact. This hypothesis was thoroughly confirmed by the results of our experimental studies of wear of different types of materials $[10,14,15]$. Based on these theoretical concepts and research facts to describe the wear kinetics of tribocoupling materials a system of ordinary differential equations is used

$$
\frac{1}{v} \frac{d h_{1}}{d t} \Phi_{1}(\tau)=1, \quad \frac{1}{v} \frac{d h_{2}}{d t} \Phi_{2}(\tau)=1
$$

where $h_{1}, h_{2}$ is the linear wear of tribocoupling elements; $t$ is the wear time; $\Phi(\tau)$ is the basic parameter of the model - wear resistance characteristic function of the material in the taken tribocouple for the selected conditions of triboprocess; $\tau$ is the specific friction force arising in tribocontact, taken as a parameter of its loading.

The determination of the specific friction force $\tau$ is carried out according to the well-known Coulomb dependence, which is widely used in 
technical applications relating to the solution of contact problems taking into account friction, as well as in tribocontact problems. It has the form

$$
\tau=f p
$$

where $f$ is the sliding friction coefficient; $p$ is the contact pressure calculated by methods of elasticity theory.

The characteristic function of the materials wear resistance $\Phi(\tau)$ according to their experimental values $\Phi_{i}\left(\tau_{i}\right)$ is approximated by the following relation

$$
\Phi_{k}(\tau)=B_{k} \frac{\tau_{0 k}^{m_{k}}}{\left(\tau-\tau_{0 k}\right)^{m_{k}}}
$$

where $B, m, \tau_{0}$ are the wear resistance characteristics of each of the materials in a tribocouple, determined by the least squares method based on a number of experimental values of this function at different levels of specific friction forces $\tau_{i} ; k=1 ; 2$ are numbers of tribocouple elements.

The experimental values of the wear resistance function $\Phi_{i}\left(\tau_{i}\right)$ are determined as follows:

$$
\Phi_{i}\left(\tau_{i}\right)=L_{i} / h_{i}
$$

where $L_{i}=v t_{i} \quad$ is the sliding distance; $i=1,2,3 \ldots$ are specific frictional force levels $\tau_{i}$.

Linear wear of samples $h_{i}$ in tribo-experimental studies of materials is determined by known methods. Maximum contact pressure $p(0, t, h)$ in the guide during wear is determined as (9)

$$
p(0, t, h)=p(0)+p(0, h) .
$$

The change in the maximum initial contact pressure $p(0, h)$ due to elements wear is calculated by the formula

$$
p(0, h)=E_{0} C_{h} \varepsilon_{h} \tan \left(\frac{\alpha_{0 h}}{2}\right),
$$

where $\varepsilon_{h}=-h_{1}\left(K_{1}+h_{1}^{\prime}\right)=-h_{2}\left(K_{2}+h_{2}^{\prime}\right) ; C_{h}$ is the wear rate indicator;

$$
\begin{aligned}
& h_{1}^{\prime}=\frac{h_{2}}{h_{1}}=\frac{\Phi_{1}(\tau)}{\Phi_{2}(\tau)}=\frac{B_{1} \tau_{01}^{m_{1}}\left(\tau-\tau_{02}\right)^{m_{2}}}{B_{2} \tau_{02}^{m_{2}}\left(\tau-\tau_{01}\right)^{m_{1}}} K_{2}, \\
& h_{2}^{\prime}=\frac{\Phi_{2}(\tau)}{\Phi_{1}(\tau)}=\frac{B_{2} \tau_{02}^{m_{2}}\left(\tau-\tau_{01}\right)^{m_{1}}}{B_{1} \tau_{01}^{m_{1}}\left(\tau-\tau_{02}\right)^{m_{2}}} K_{1} ;
\end{aligned}
$$

$\tau=f p(0)=f E_{0} \varepsilon \tan \left(\alpha_{0} / 2\right) \quad$ is the maximum specific friction force acting at the beginning of the wear process at $t=0$.

Then the maximum tribocontact pressure $p(0, t, h)$ is

$$
p(0, t, h)=E_{0}\left[\varepsilon \tan \left(\frac{\alpha_{0}}{2}\right)+C_{h} \varepsilon_{h} \tan \left(\frac{\alpha_{0 h}}{2}\right)\right] .
$$

The tribocontact semiangle $\alpha_{0 h}$ is determined by the equation (12)

$$
N=4 \pi R_{2} E_{0}\left(\varepsilon+C_{h} \varepsilon_{h}\right) \sin ^{2} \frac{\alpha_{0 h}}{4},
$$

As a result of the integration of system (5), taking into account the dependences (6), (7), (9), (11), the guide service life $t^{*}$ before reaching the allowable wear $h_{k *}$ by one of its elements is calculated by formula (13)

$$
t_{*}=\frac{-B_{k} \tau_{0 k}^{m_{k}}}{v C_{h} \tau_{0 h}\left(1+h_{k}^{\prime}\right)\left(1-m_{k}\right) K_{k}}\left\{\left(\tau-\tau_{0 k}\right)^{1-m_{k}}-\left[\left(\tau-\tau_{0 k}\right)+\varepsilon_{h} C_{h} \tau_{0 h}\right]^{1-m_{k}}\right\},
$$

where $\tau_{0 h}=f \mid p(0, h \mid$.

For this type of tribomechanical sliding system it is more expedient to determine the limiting sliding distance $L^{*}$ as the service life of the bushing until it reaches the allowable wear

$$
L_{1 *}=\frac{-B_{1} \tau_{01}^{m_{1}}}{C_{h} \tau_{0 h}\left(1+h_{1}^{\prime}\right)\left(1-m_{1}\right) K_{1}}\left\{\left(\tau-\tau_{01}\right)^{1-m_{1}}-\left[\left(\tau-\tau_{01}\right)+\varepsilon_{h} C_{h} \tau_{0 h}\right]^{1-m_{1}}\right\} .
$$

The wear $h_{2}$ of the guide base 2 during the sliding distance $L *$ is calculated as follows:

$$
h_{2}=h_{1} h_{1}^{\prime} / K_{1} \text {, }
$$




\section{SOLUTION, RESULTS AND DISCUSSIONS}

According to [16], the diameter of cylindrical guide base can be in the range of $30 \ldots 120 \mathrm{~mm}$. Number of guides is ranged from 1 to 4 .

Data for calculation: $F=500,750,1000,2000 \mathrm{~N}$; $N=F / l_{1}=5,7.5,10,20 \mathrm{~N} / \mathrm{mm}, l_{1}=100 \mathrm{~mm}-$ bushing length, $l_{2}=500 \mathrm{~mm}-$ base length; $\varepsilon=$ $0.05,0.075,0.1 \mathrm{~mm}$ (clearance fit H9/d9); $D 2=$ $40,50 \mathrm{~mm} ; f=0.09$ - boundary friction; $h_{1 *}=0.5$ $\mathrm{mm}$. The view of the guide is shown in Fig. $1 \mathrm{~b}$.

Materials of tribosystem elements:

- slider bushing: polymer composites Moglice and DK6; Moglice $-E_{M}=11200 \mathrm{MPa}, \mu_{M}=0.4, R_{m}$ $=120 \mathrm{MPa}$, DK6 $-E_{D K}=6500 \mathrm{MPa}, \mu_{D K}=0.4, R_{m}=$ $140 \mathrm{MПа;} B_{1}=1.2 \cdot 10^{11}, m_{1}=1.9, \tau_{01}=0.05 \mathrm{MPa}-$ their wear resistance characteristics;

- base: carbon steel $S 45-E_{2}=210000 \mathrm{MPa}, \mu_{2}=$ $0.3 ; m_{2}=2.1, \tau_{02}=0.1 \mathrm{MПа,} B_{2}=2.2 \cdot 10^{12}, m_{2}=$ 2.1, $\tau_{01}=0.1 \mathrm{MPa}$.

The anti-friction polymer epoxy material DIAMANT Moglice (DIAMANT Metallplastic $\mathrm{GmbH}$ ) of cold hardening is used for sliding friction units, and also for their renovation. Fillers such as molybdenum disulfide, graphite, and others are used in the DK6 polymer epoxy composite.

The results of calculations of the maximum contact pressures $p(0)$ and their decrease $p(0, t, h)$ due to wear of the slider, angles $\alpha_{0}$ of the initial contact and its change $\alpha 0 \mathrm{~h}$ during wear of the slider, service life of the cylindrical guide are given in Fig. 3 - 7. Solid lines show curves for $D_{2}$ $=40 \mathrm{~mm}$, and dashed lines - for $D_{2}=50 \mathrm{~mm}$. Figures (a) correspond to Moglice composite, and figures (b) - DK6.

Figure 3 shows the initial maximum contact pressure $p(0)$ dependencies on load $N$ at different radial clearances $\varepsilon$ in the connection. There are close to linear dependences of $p(0)$ on $N$ at different radial clearances for both investigated diameters.

The initial contact pressures are reduced when the wear of the composite slider bushing $h_{1^{*}}=0.5$ $\mathrm{mm}$ is achieved. Fig. 4 shows the quantitative and qualitative nature of these changes.

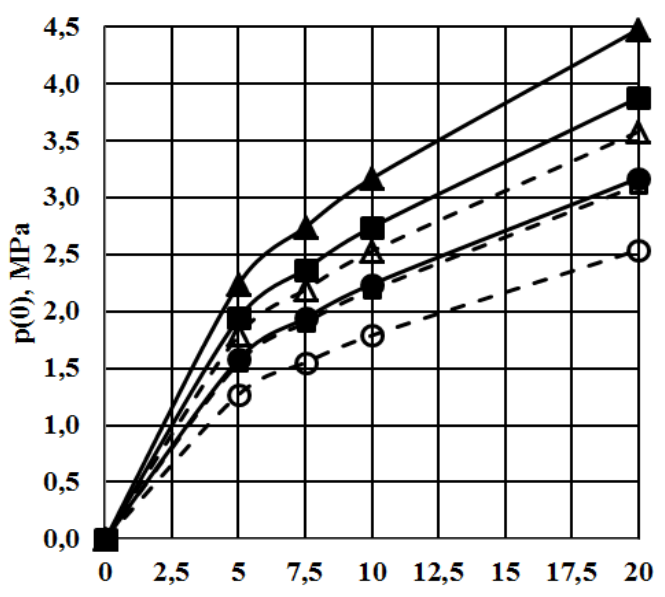

a)

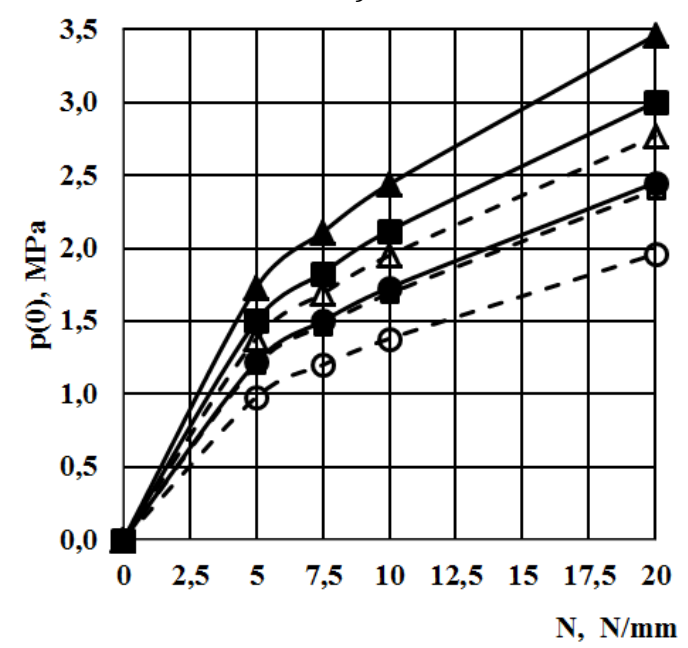

b)

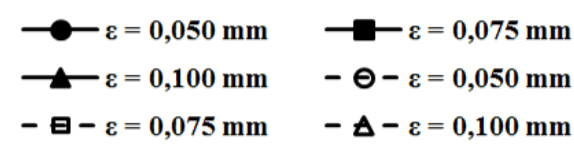

Fig. 3. Dependencies of the initial maximum contact pressure $p(0)$ on load $N$ and radial clearances $\varepsilon$

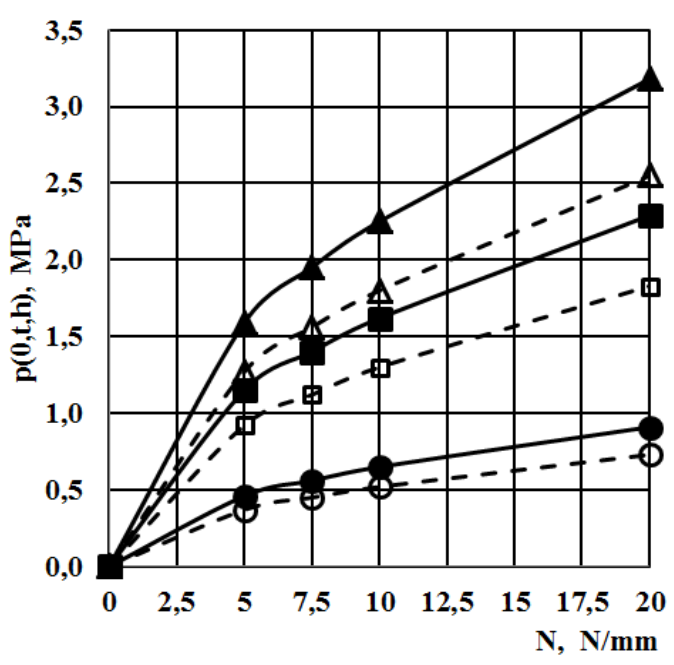

a) 


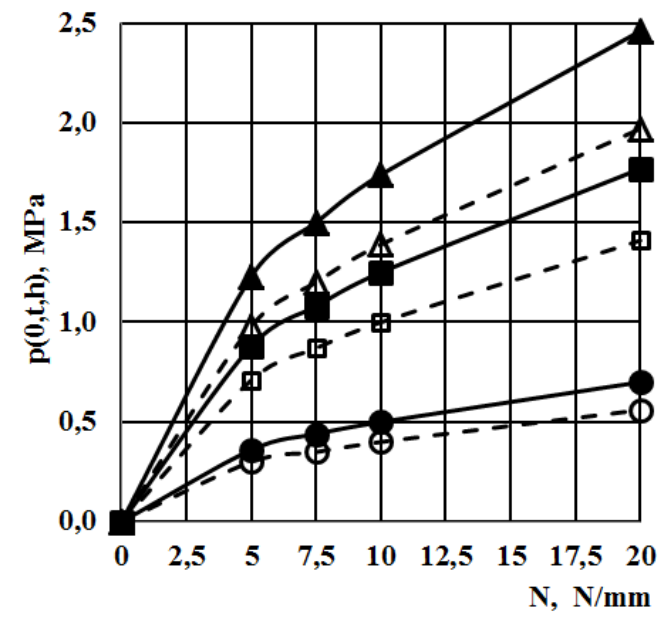

b)

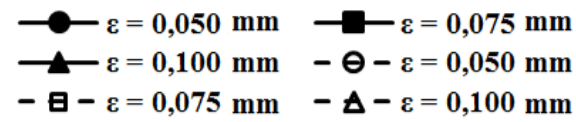

Fig. 4. Influence of bushing wear on change of initial maximum contact pressures

As for the pressures $p(0)$, the tribocontact pressures $p(0, t, h)$ depend almost linearly on load $N$. However, their change is significantly larger at lower values of the radial clearances $\varepsilon$ in the joint.

Figure 5 shows the dependence of the initial contact angle $\alpha_{0}$ on the load and the radial clearance. The qualitative nature of the increase in $\alpha_{0}$ is similar to the increase in pressure $p(0)$ (Fig. 3), i.e. is almost linear. However, here, when the base diameter $D_{2}$ changes, the radial clearance $\varepsilon$ at the same load does not affect the value of $\alpha_{0}$, which is regular according to equation (4). The bushing wear leads to an increase in the initial contact semiangle (Fig. 6).

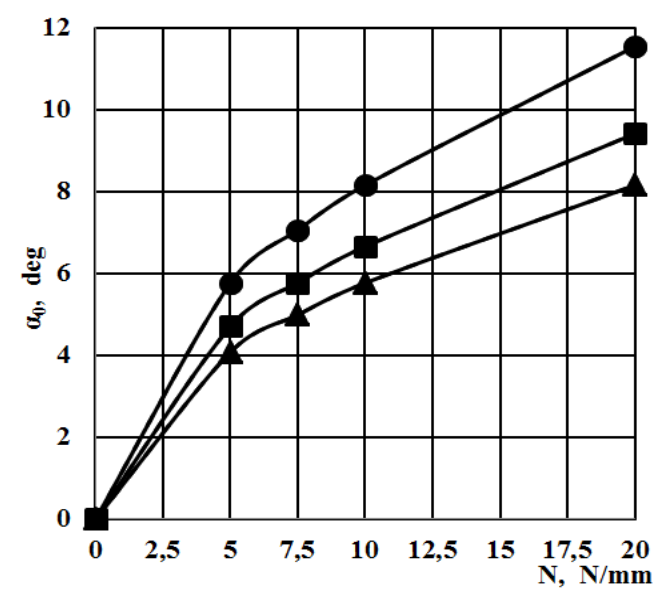

a)

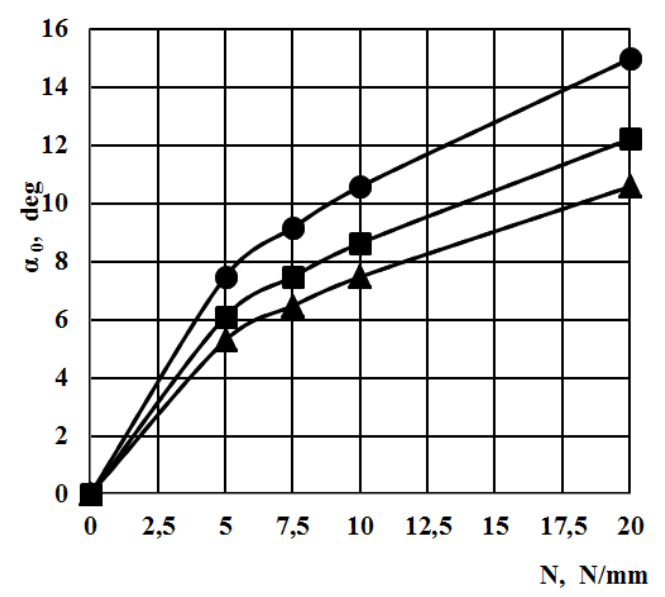

b)

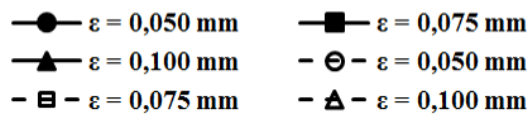

Fig. 5. Dependence of $\alpha_{0}$ on $N$ and $\varepsilon$

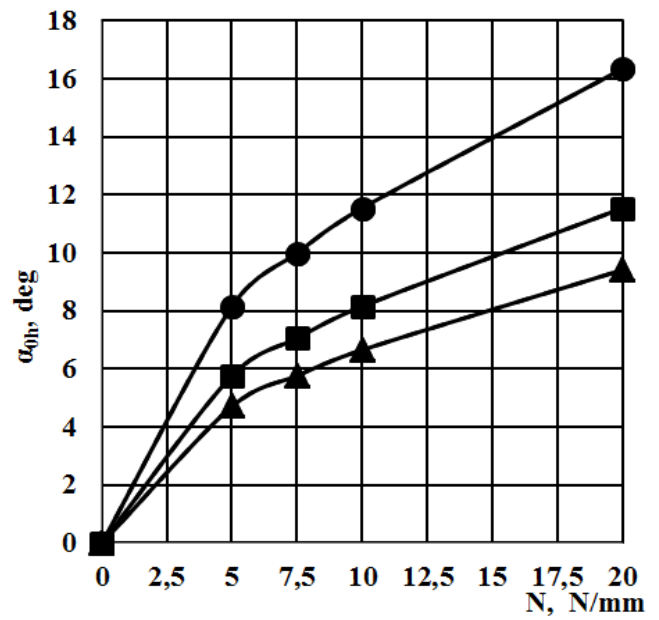

a)

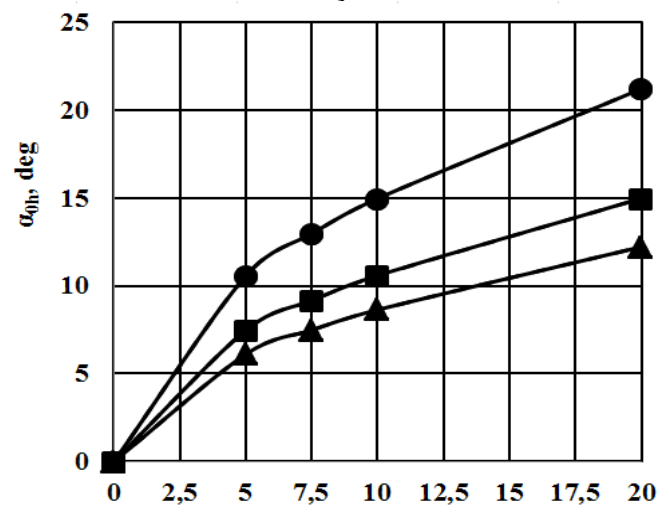

b)

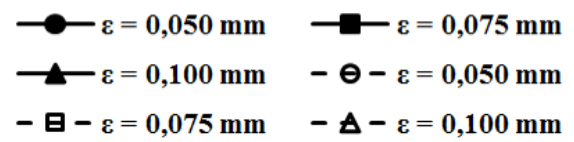

Fig. 6. Influence of the bushing wear on change of initial contact semiangles 
When the bushing wears, the increase in load leads to a linear increase in the angle $\alpha_{0 h}$.

The influence of the load $N$ and clearance $\varepsilon$ on the guide durability $L_{1}$ until the bushing 1 reaches the allowable wear $h_{1^{*}}=0.5 \mathrm{~mm}$ is shown in Fig. 7.

There is a pronounced nonlinear nature of the decrease in $L_{1}$ with increasing load $\mathrm{N}$, especially at low $\varepsilon$. Also durability significantly depends on the diameter of the bushing, i.e. it increases with diameter increasing. The results of the calculations will be presented in the form of tables 1 and 2 for materials Moglice and DK6, respectively.

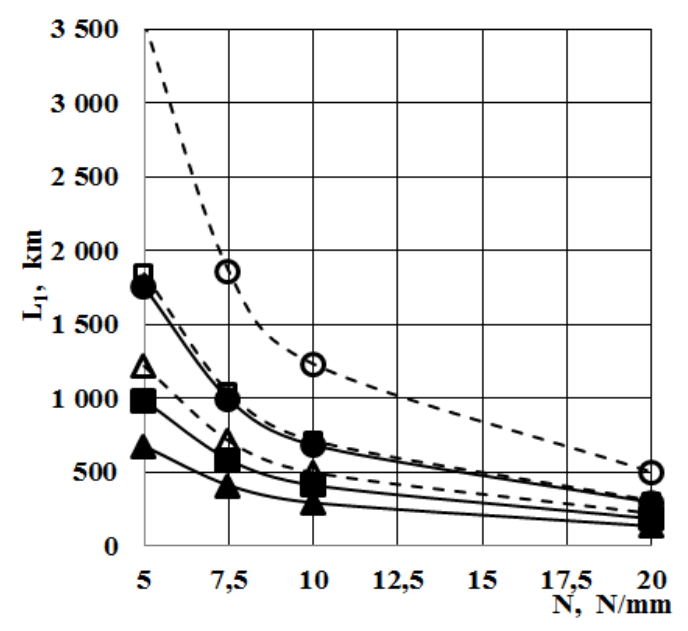

a)

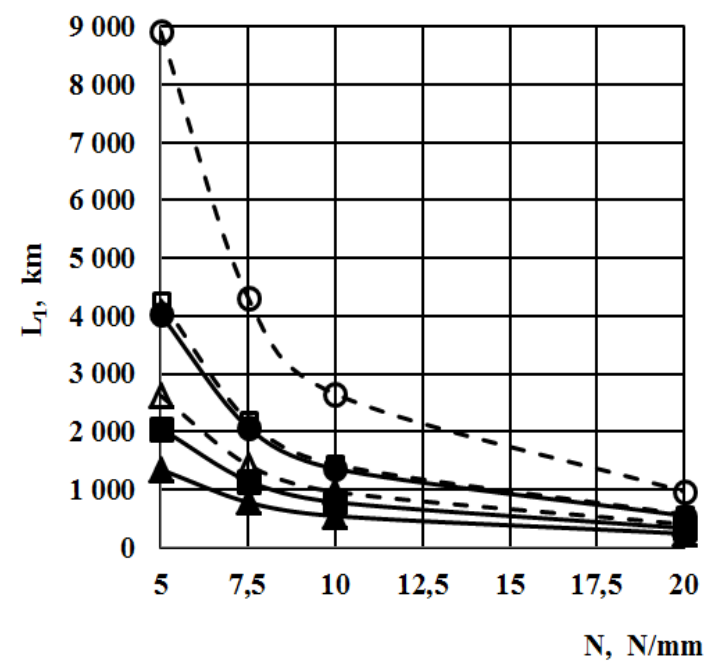

b)

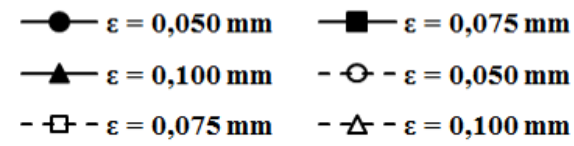

Fig. 7. Dependence of $L_{1}$ on $N$ and $\varepsilon$
Table 1. Guide resource $L_{1(\mathrm{M})}$ for a bushing made of Moglice

\begin{tabular}{|c|c|c|c|c|c|c|}
\hline $\begin{array}{c}\mathbf{N}, \\
\mathbf{N} / \mathbf{m m}\end{array}$ & \multicolumn{7}{|c|}{ Sliding distance $\mathbf{L}_{\mathbf{1}}, \mathbf{k m}$} \\
\hline 5 & 1757 & 987 & 678 & 3548 & 1846 & 1219 \\
\hline 7,5 & 996 & 586 & 412 & 1864 & 1042 & 713 \\
\hline 10 & 685 & 413 & 294 & 1234 & 715 & 499 \\
\hline 20 & 297 & 186 & 136 & 503 & 309 & 222 \\
\hline$\varepsilon, \mathrm{mm}$ & 0,05 & 0,075 & 0,1 & 0,05 & 0,075 & 0,1 \\
\hline $\begin{array}{c}\text { Increase } \\
N, \text { times }\end{array}$ & \multicolumn{7}{|c|}{$D_{2}=40 \mathrm{~mm}$} & \multicolumn{3}{|c|}{$D_{2}=50 \mathrm{~mm}$} \\
\cline { 2 - 7 } & \multicolumn{7}{|c|}{ Decrease $L_{1}$, times } \\
\hline $\mathbf{4}$ & $\mathbf{5 , 9 2}$ & $\mathbf{5 , 3 0}$ & $\mathbf{4 , 9 9}$ & $\mathbf{7 , 0 6}$ & $\mathbf{5 , 9 8}$ & $\mathbf{5 , 4 9}$ \\
\hline
\end{tabular}

Table 2. Guide resource $L_{1(\mathrm{DK})}$ for a bushing made of DK6

\begin{tabular}{|c|c|c|c|c|c|c|}
\hline $\begin{array}{c}\boldsymbol{N}, \\
\mathbf{N} / \mathbf{m m}\end{array}$ & \multicolumn{7}{|c|}{ Sliding distance $\mathbf{L}_{\mathbf{1}}, \mathbf{k m}$} \\
\hline 5 & 4026 & 2060 & 1350 & 8918 & 4275 & 2624 \\
\hline 7,5 & 2079 & 1151 & 783 & 4320 & 2190 & 1429 \\
\hline 10 & 1365 & 785 & 545 & 2656 & 1433 & 963 \\
\hline 20 & 548 & 336 & 241 & 969 & 573 & 404 \\
\hline$\varepsilon, \mathrm{mm}$ & 0,05 & 0,075 & 0,1 & 0,05 & 0,075 & 0,1 \\
\hline $\begin{array}{c}\text { Increase } \\
N, \text { times }\end{array}$ & \multicolumn{7}{|c|}{$D_{2}=40 \mathrm{~mm}$} & $D_{2}=50 \mathrm{~mm}$ \\
\cline { 2 - 6 } & \multicolumn{7}{|c|}{ Decrease $L_{1}$, times } \\
\hline $\mathbf{4}$ & $\mathbf{7 , 3 4}$ & $\mathbf{6 , 1 4}$ & $\mathbf{5 , 6 1}$ & $\mathbf{9 , 2 0}$ & $\mathbf{7 , 4 6}$ & $\mathbf{6 , 5 0}$ \\
\hline
\end{tabular}

If we compare tables 1 and 2 we can note that the resource of the guide bushing made of DK6 is 2.51...1.77 times greater than the resource of the guide bushing made of Moglice (Table 3 ).

Table 3. The impact of load on the relative reduction of resources $L_{1}(\mathrm{DK}) / L_{1}(\mathrm{M})$

\begin{tabular}{|c|c|c|c|c|c|c|c|}
\hline $\begin{array}{c}\text { Compo- } \\
\text { site }\end{array}$ & \begin{tabular}{|c|}
$\mathbf{N}$, \\
$\mathrm{N} / \mathrm{mm}$
\end{tabular} & \multicolumn{6}{|c|}{ Sliding distance $L_{1}, \mathrm{~km}$} \\
\hline DK6 & 5 & 4026 & 2060 & 1350 & 8918 & 4275 & 2624 \\
\hline Moglice & 5 & 1757 & 987 & 678 & 3548 & 1846 & 1219 \\
\hline \multicolumn{2}{|c|}{$L_{1(\mathrm{DK})} / L_{1(\mathrm{M})}$, times } & 2,29 & 2,09 & 1,99 & 2,51 & 2,32 & 2,15 \\
\hline DK6 & 7,5 & 2079 & 1151 & 783 & 4320 & 2190 & 1429 \\
\hline Moglice & 7,5 & 996 & 586 & 412 & 1864 & 1042 & 713 \\
\hline \multicolumn{2}{|c|}{$L_{1(\mathrm{DK})} / L_{1(\mathrm{M})}$, times } & 2,09 & 1,96 & 1,90 & 2,32 & 2,10 & 2,00 \\
\hline DK6 & 10 & 1365 & 785 & 545 & 2656 & 1433 & 963 \\
\hline Moglice & 10 & 685 & 413 & 294 & 1234 & 715 & 499 \\
\hline \multicolumn{2}{|c|}{$L_{1(\mathrm{DK})} / L_{1}(\mathrm{M})$, times } & 1,99 & 1,90 & 1,85 & 2,15 & 2,00 & 1,93 \\
\hline DK6 & 20 & 548 & 336 & 241 & 969 & 573 & 404 \\
\hline Moglice & 20 & 297 & 186 & 136 & 503 & 309 & 222 \\
\hline \multicolumn{2}{|c|}{$L_{1(\mathrm{DK})} / L_{1(\mathrm{M})}$, times } & 1,85 & 1,81 & 1,77 & 1,93 & 1,85 & 1,82 \\
\hline \multicolumn{2}{|c|}{$\begin{array}{l}\text { Radial clearance } \\
\varepsilon, \mathrm{mm}\end{array}$} & 0,05 & 0,075 & 0,1 & 0,05 & 0,075 & 0,1 \\
\hline \multicolumn{2}{|c|}{ Diameter $D_{2}, \mathrm{~mm}$} & \multicolumn{3}{|c|}{40} & \multicolumn{3}{|c|}{50} \\
\hline
\end{tabular}




\section{CONCLUSION}

According to the results of the analysis of the calculations, the following quantitative regularities of the effect of load, bushing diameter and radial clearance in the guide on the contact parameters and resource are established:

\section{Maximum contact pressures $p(0), p(0, t, h)$}

1. When the load increases 4 times, the initial maximum contact pressures $p(0)$ increase $\sqrt{4}$ $=2$ times, and doubling the radial clearance $\varepsilon$ leads to their growth by $\sqrt{2}$ times regardless of changes in the load, the base diameter $D_{2}$ and the type of composite material (Fig. 3).

2. When the base diameter $D_{2}$ increases by 1.25 times, the pressure $p(0)$ decreases by the same amount (Fig. 3).

3. As a result of the bushing wear, the initial pressures $p(0)$ are reduced by 3.43 ...3.49 times depending on the value of the radial clearance $\varepsilon$. When the load increases fourfold the pressures $p(0, t, h)$ will also double, as will the pressures $p(0)$ (Fig. 4).

4. For a guide with a bushing made of Moglice there are 1.3 times higher pressures $p(0)$ $\left(\approx \sqrt{E_{M} / E_{D K}}\right)$ than for a bushing made of DK6, which is due to the larger value of the Young's modulus of Moglice.

\section{Contact semiangles $\alpha_{0}, \alpha_{0 h}$}

1. With a load increase of 4 times, the angles $\alpha_{0}$ double, and the increase of the radial clearance twice causes the angle $\alpha_{0}$ to decrease $\sqrt{2}$ times for all load values (Fig. 5).

2. The bushing wear leads to an increase in the angle $\alpha_{0 h}$ twice with increasing load four times, and doubling the clearance - to a decrease in the angle $\alpha_{0 h}$ in 1.73 times, which is approximately equal to $E_{M} / E_{D K}$ (Fig. 6).

\section{Sliding distance $L_{1}$ (guide resource)}

1. When the load is quadrupled, the sliding distance is significantly reduced by $4.99 . . .7 .06$ times (Moglice) and 5.61...9.2 times (DK6) depending on the radial clearance in the joint and the base diameter (Fig. 7; Table 1; 2).
2. The resource of the guide bushing made of DK6 is 2.51...1.77 times greater than the resource of the guide bushing made of Moglice (Table 3 ).

The possibility of effective research of both hybrid (metal-polymer) and metal cylindrical sliding guides is realized by using the developed computational method.

\section{REFERENCES}

[1] I.G. Goryacheva, N.M. Dobychin, Contact problems in tribology, Moscow: Mashinostroyeniye, 1988. (in Russian)

[2] M.I. Tepliy, Determination of contact parameters and wear in cylindrical sliding bearings, Friction and Wear, no. 6, pp. 895-902, 1987. (in Russian)

[3] A.G. Kuzmenko, Development of methods of contact tribomechanics, Moscow: Mashinostroyeniye, 1988. (in Russian)

[4] R.V. Sorokatyi, Modeling the behavior of tribosystems using the method of triboelements, Journal of Friction and Wear, vol. 23, iss. 1, pp. 16-22, 2002.

[5] R.V. Sorokatyi, V.G. Pisarenko, M.A. Dykha, Analysis of Wear Surface Geometry Formation in Plain Bearings with Misaligned Shaft and Bush Axes, Journal of Friction and Wear, vol. 34 , iss. 4, pp. 274-280, 2013, doi: $10.3103 /$ S1068366613040119

[6] R.V. Sorokatyi, Evaluation of efficiency of sliding bearings during reciprocation, Journal of Friction and Wear, vol. 24, iss. 1, pp. 15-21, 2003.

[7] M.V. Chernets, On the issue of assessing the durability of cylindrical sliding tribosystems with boundaries close to circular, Friction and Wear, no. 3, pp. 340-344, 1996.

[8] M.V. Chernets, N.M. Lebedeva, To the question of the effect of small non-circularity of elements of a cylindrical guide on its durability, Problems of Tribology, no. 3, pp. 100-106, 2005. (in Russian)

[9] M.V. Chernets, N.M. Lebedeva, Investigation of the influence of small non-roundness on the resource of a cylindrical guide, Problems of Tribology, no. 4, pp. 52-55, 2006. (in Ukrainian)

[10] M.V. Chernets, Tribo-contact tasks for cylindrical joints with technological non-circularity, Lublin: Lublin Polytechnic, 2013.

[11] M.V. Chernets, O.E. Andreikiv, N.M. Liebiedieva, V.B. Zhydyk, A model for evaluation of wear and durability of plain bearing with small non-circularity of its contours, Materials Science, iss. 2, pp. 279-290, 2009, doi: 10.1007/s11003-009-9176-5 
[12] M.V. Chernets, Contact problem for a cylindrical joint with technological faceting of the contours of its parts, Materials Science, iss. 6, pp. 859-868, 2009, doi: 10.1007/s11003-010-9252-x

[13] M. Chernets, Ju. Chernets, Generalized method for calculating the durability of sliding bearings with technological out-of-roundness of details, Proceedings of the Institution of Mechanical Engineers, Part J: Journal of Engineering Tribology, vol. 229, iss. 2, pp. 216-226, 2015, doi: 10.1177/1350650114554242

[14] A.E. Andreikiv, M.B. Chernets, Evaluation of contact interaction of friction elements of machines, Kiev: Naukova dumka, 1991. (in Ukrainian)

[15] M. Chernets, K. Lenik, On estimation of materials durability, Materials Science, iss. 6, pp. 834840, 1997, doi: 10.1007/BF02355563

[16] V.P. Velboy, M.O. Dikha, To calculate the contact parameters and friction forces in cylindrical sliding guides, Problems of Tribology, no. 4, pp. 82-88, 2016. (in Ukrainian)

[17] A. Azzi, A. Maoui, A. Fatu, S. Fily, D. Souchet, Experimental study of friction in pneumatic seals, Tribology International, vol. 135, pp. 432-443, 2019, doi: 10.1016/j.triboint.2019.03.018

[18] G. Belforte, M. Conte, A. Manuello, L. Mazza, Performance and behavior of seals for pneumatic spool valves, Tribology Transactions, vol. 54, iss. 2, pp. 237-246, 2011, doi: 10.1080/10402004.2010.538488

[19] G. Belforte, A. Manuello, L. Mazza, Test rig for friction force measuremets in pneumatic components and seals, Proceedings of the Institution of Mechanical Engineers, Part J: Journal of Engineering Tribology, vol. 227, iss. 1, pp. 43-59, 2012, doi: $10.1177 / 1350650112453522$

[20] C. Calvert, M. Tirovic, T. Stolarski, Design and Development of an Elastomer-Based Pneumatic Seal Using Finite Element Analysis, Proceedings of the Institution of Mechanical Engineers, Part J: Journal of Engineering Tribology, vol. 216, iss. 3, pp. 127-138, 2002, doi: $10.1243 / 1350650021543951$
[21] C. Cristescu, C. Dumitrescu, R. Radoi, L. Dumitrescu, Experimental Research for Measuring Friction Forces from Piston Sealing at the Hydraulic Cylinders, Tribology in Industry, vol. 36, no. 4, pp. 465-474, 2014.

[22] P.J. Gamez-Montero, E. Salazar, R. Castilla, et all, Friction effects on the load capacity of a column and a hydraulic cylinder, International Journal of Mechanical Science, vol. 51, iss. 2, pp. 145-151, 2009, doi: 10.1016/j.ijmecsci.2008.12.007

[23] H. Chang, C.-W. Lan, C.-H. Chen, T.-T. Tsung, J.-B. Guo, Measurement of frictional force characteristics of pneumatic cylinders under dry and lubricated conditions, Electrical Review, vol. 88, no. 7, pp. 261-264, 2012.

[24] M. Lorinc, F. Szabolcs, S. Nariman, A practical method for friction identification in hydraulic actuators, Mechatronics, vol. 21, iss. 1, pp. 350-356, 2011, doi: 10.1016/j.mechatronics.2010.08.010

[25] P. Sekhavat, Q. Wu, N. Sepehri, Lyapunov-based friction compensation for accurate positioning of a hydraulic actuator, in Proceedings of 2004 American control conference, 30 June-2 July, 2004, Boston, Massachusetts, USA doi: 10.23919/acc.2004.1383638

[26] S. Tafazoli, de C.W. Silva, P.D. Lawrence, Tracking control of an electrohydraulic manipulator in the presence of friction, IEEE Trans Control Syst Technol, vol. 6 (3), pp. 401411, 1998, doi: 10.1109/87.668040

[27] X.B. Tran, N.N. Hafizah., Y.H. Yanada, Modeling of dynamic friction behaviors of hydraulic cylinders, Mechatronics, vol. 22, iss. 1, pp. 65-75, 2012, doi: 10.1016/j.mechatronics.2011.11.009

[28] B. Verheyde, A. Vanhulsel, M. Rombousts, J. Meneve, D. Havermans, M. Wangenheim Lawrence, Influence of surface treatment of elastomers on their frictional behaviour in sliding contact, Wear, vol. 266, iss. 3-4, pp. 468-475, 2008, doi: 10.1016/j.wear.2008.04.040 